\title{
Primary immunisations in Liverpool. II: Is there a gap between consent and completion?
}

Maggie Pearson, Krystyna Makowiecka, Jacqueline Gregg, Jane Woollard, Michael Rogers, Chris West

\begin{abstract}
The association between completion of primary diphtheria, tetanus and pertussis, measles, mumps, and rubella and polio immunisation courses in Liverpool and five sociodemographic factors, namely the child's sex, position in the family, family type, migration into Liverpool since birth, and local deprivation was examined.

Only $68 \%$ of children were fully immunised by their second birthday. The immunisation rate for pertussis was $74 \%$, compared with $85-$ $89 \%$ for the other antigens. Children who had older siblings, were recorded as living with one parent, had moved into Liverpool or who lived in areas of high deprivation were less likely to complete the full set of antigens and individual courses. Boys were significantly less likely than girls to be fully immunised against pertussis.
\end{abstract}

Differences in the completion of pertussis immunisation associated with the child's sex and with local deprivation were a direct reflection of differences in rates of parental consent. Parental consent did not wholly account for significantly lower rates among children with older siblings, those living with a lone parent, and those who had moved into Liverpool, however. This may reflect the practical difficulties of attending immunisation clinics. To achieve immunisation targets, a more flexible and targeted approach is required of health professionals. This may include the careful targeting of efforts to increase consent and the improvement of access to immunisations by providing domiciliary services or by opportunistic immunisation of infants when they are in contact with primary and community health care services.

Department of General Practice, University of Liverpool

M Pearson

K Makowiecka

Royal Liverpool Children's NHS Trust J Gregg

J Woollard

Department of Child Health, University of Liverpool

M Rogers

Department of Public Health, University of Liverpool

C West

Correspondence to: Dr Maggie Pearson, Department of Nursing University of Liverpool, $P O$ Box 147, Liverpool L69 3BX. Accepted 3 March 1993
In 1989-90, two year immunisation rates among children in Liverpool born in 1987-8 were lowest in the Mersey region and were among the lowest in the country, with $81 \%$ for DTPol, $67 \%$ for pertussis, and $73 \%$ for measles. ${ }^{2}$
As in all other health districts, immunisation rates in Liverpool with the measles, mumps, and rubella (MMR) vaccine, introduced in October 1988, was lower than all other antigens at $55 \%$. Following a concerted effort to improve immunisations locally, two year course completion rates had increased by March 1991 to $89 \%$ for DTPol, $79 \%$ for pertussis, and $84 \%$ for measles/MMR. ${ }^{3}$

A detailed analysis of primary immunisation in Liverpool led us to distinguish between the effects of a child's social and personal circumstances on consent, ${ }^{4}$ and on two year completion rates, which we now report. We examined completion rates for the whole cohort and in relation to recorded consent for specific antigens. We use the term 'consent' to indicate recorded agreement by parents to be included in a computerised invitation and appointments system, to which parents respond by presenting their child for immunisation. This is in line with current advice from the Department of Health. ${ }^{5}$

Subjects and methods

The immunisation records of children who were born between 1 April and 1 October 1988 inclusive and resident within Liverpool District Health Authority in September 1991 were obtained from data on the vaccination and immunisation module of the National Child Health System. This cohort was selected for the reasons reported in our first study..$^{46}$

These children would have been invited to receive DTPol and pertussis immunisations at 3 , 5 , and 8 months, and the MMR vaccine at 1 year of age. For each child, personal data and operational details of their immunisation history were extracted. Operational details included the parental consent code, which indicated the specific antigens for which consent was given, and details of antigen doses given. Personal data included five sociodemographic variables: the child's sex, family position (inferred from the mother's parity at the child's birth), recorded family type (lone or two parent), migration into Liverpool, and current electoral ward. Data on ethnic origin and parents' social class were not available on the computer records.

As in our first study, the overall deprivation index $(\mathrm{ODI})^{7}$ was used to indicate the child's socioeconomic status and wards divided on the basis of their deprivation scores.

The data were downloaded onto a microcomputer and analysed using the Epi-Info package $^{8}$ to calculate two year immunisation completion rates. Completion rates were calculated for the entire cohort (cohort completion rates) and specifically for those for whom consent was recorded for immunisation (consent based 
Table 1 Cohort completion rates at second birthday

\begin{tabular}{lll}
\hline Antigen & $\begin{array}{l}\text { National } \\
1989-90(\%)\end{array}$ & $\begin{array}{l}\text { No(\%) in Liverpool district } \\
\text { health authorityt } 1990 \\
(\boldsymbol{n}=3585)\end{array}$ \\
\hline Diphtheria & 89 & $3130(87)$ \\
Tetanus & 89 & $3134(87)$ \\
Polio & 89 & $3129(87)$ \\
Pertussis & 78 & $2664(74)$ \\
MMR & 84 & $2987(83)$ \\
All antigens & Not available & $2439(68)$ \\
\hline
\end{tabular}

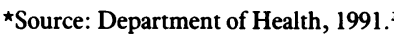

tRounded to nearest whole number.

$\Varangle$ National rate for measles only.

completion rates). In addition, cohort and consent based completion rates were calculated for specific antigens. The Arcus package ${ }^{9}$ was used to conduct $\chi^{2}$ tests (including for trend).

National, regional, and district immunisation figures are usually reported separately for specific antigens. ${ }^{2}$ Although this information is meaningful in terms of the population's protection against individual diseases, the rate of full immunisation against all the preventable diseases in the immunisation programme is also of concern for the protection of the individual child. Antigen specific and 'composite' (all antigens) two year immunisation rates were therefore calculated by sex, family position, family type, mobility, and ward deprivation index. As preliminary data analysis confirmed that the course completion rates for diphtheria, tetanus, and polio were almost identical, these three antigens were considered together, whereas completion of pertussis and MMR were considered separately.

The SAS statistical package ${ }^{10}$ was used to fit binary logistic regression models ${ }^{11}$ to the data to assess the strength of association of each individual factor with immunisation uptake after controlling for the effect of the other factors and to estimate odds ratios. The odds ratios of completing antigen specific and the full set of primary courses were calculated. An odds ratio of unity indicates that there is no association between the factor and course completion. Any variable for which the $95 \%$ confidence limits include a value of unity are thus considered not to have a significant effect on the completion of immunisation courses.

\section{Results}

COURSE COMPLETION RATES

In 1990 two year immunisation rates in Liverpool for each antigen were slightly lower than the national rates for England in 1989-902 (table 1). Local immunisation rates for pertussis, for which fewer than $75 \%$ of children completed the course, were lower than the national rate by a greater margin $(4 \%)$ than the other antigens. Completion rates for the full set of antigens (composite completion) are not available nationally, but in Liverpool $68 \%$ of children were immunised with all antigens, a lower rate than for any individual antigen. Table 1 shows the cohort course completion rate for each individual antigen.

\section{VARIABLES ASSOCIATED WITH COURSE}

\section{COMPLETION}

Composite completion rates decreased sharply with increasing number of older siblings and with increasing local deprivation. Children recorded as living with a lone parent were less likely to have completed the full set of immunisations than those recorded as living with two parents, as were children who moved into Liverpool compared with those who were resident in Liverpool from birth. Sex was the only variable not significantly associated with completed courses of the full set of antigens (table 2).

Family position, family type, and migration into Liverpool were significantly associated with completion of all individual antigens. Completion of DTPol and pertussis immunisations were also significantly associated with local deprivation. Pertussis was the only antigen for which the child's sex was significantly associated with course completion, girls being more likely to be immunised than boys. Deprivation was not significantly associated with completion rates for MMR.

Table 2 Sociodemographic factors and completion of primary immunisation courses

\begin{tabular}{|c|c|c|c|c|}
\hline \multirow[b]{2}{*}{ Factor } & \multicolumn{4}{|c|}{ Course completion rate $(\%(\mathrm{No}))$} \\
\hline & DTPol & Pertussis & $M M R$ & All antigens \\
\hline$\overline{\text { Sex }}$ & & $\star \star$ & & \\
\hline $\begin{array}{l}\text { Girls } \\
\text { Boys } \\
\text { Family position }\end{array}$ & $\begin{array}{l}88 \cdot 0(1508 / 1714) \\
86 \cdot 2(1613 / 1871) \\
\star \star \star\end{array}$ & $\begin{array}{l}76 \cdot 0(1303 / 1714) \\
72 \cdot 7(1361 / 1871) \\
\star \star \star\end{array}$ & $\begin{array}{l}83 \cdot 4(1430 / 1714) \\
83 \cdot 2(1557 / 1871) \\
\star \star \star\end{array}$ & $\begin{array}{l}69 \cdot 5(1192 / 1714) \\
66 \cdot 6(1247 / 1871)\end{array}$ \\
\hline $\begin{array}{l}\text { First child } \\
\text { Second child } \\
\text { Third child } \\
\text { Fourth child and above }\end{array}$ & $\begin{array}{l}92 \cdot 5(1303 / 1408) \\
87 \cdot 4(1013 / 1159) \\
82 \cdot 7(464 / 561) \\
77 \cdot 8(281 / 361) \\
\star \star \star\end{array}$ & $\begin{array}{l}83 \cdot 6(1177 / 1408) \\
74 \cdot 4(862 / 1159) \\
64 \cdot 0(359 / 561) \\
58 \cdot 2(210 / 361) \\
\star \star \star\end{array}$ & $\begin{array}{l}88 \cdot 3(1243 / 1408) \\
84 \cdot 2(976 / 1159) \\
78 \cdot 1(438 / 561) \\
73 \cdot 4(265 / 361) \\
\star \star \star\end{array}$ & $\begin{array}{l}76 \cdot 9(1083 / 1408) \\
68 \cdot 9(798 / 1159) \\
57 \cdot 8(324 / 561) \\
51 \cdot 2(185 / 361)\end{array}$ \\
\hline $\begin{array}{l}\text { Lone parent } \\
\text { Two parents } \\
\text { Migration into Liverpool }\end{array}$ & $\begin{array}{l}85 \cdot 1(1082 / 1271) \\
89 \cdot 0(1947 / 2188) \\
\star \star \star\end{array}$ & $\begin{array}{l}70 \cdot 9(901 / 1271) \\
76 \cdot 9(1682 / 2188) \\
\star \star \star\end{array}$ & $\begin{array}{l}80 \cdot 6(1024 / 1271) \\
85 \cdot 6(1873 / 2188) \\
\star \star \star\end{array}$ & $\begin{array}{l}64 \cdot 4(818 / 1271) \\
71 \cdot 1(1555 / 2188)\end{array}$ \\
\hline $\begin{array}{l}\text { Resident at birth } \\
\text { Moved in since birth } \\
\text { Deprivation } f\end{array}$ & $\begin{array}{l}88 \cdot 2(2906 / 3294) \\
73 \cdot 9(215 / 291) \\
\star \star \star\end{array}$ & $\begin{array}{l}75 \cdot 1(2473 / 3294) \\
65 \cdot 6(191 / 291) \\
\star \star \star\end{array}$ & $\begin{array}{l}84 \cdot 7(2789 / 3294) \\
68 \cdot 0(198 / 291)\end{array}$ & $\begin{array}{l}69 \cdot 3(2284 / 3294) \\
53 \cdot 3(155 / 291)\end{array}$ \\
\hline $\begin{array}{l}\text { Most deprived } \\
\text { Deprived } \\
\text { Least deprived }\end{array}$ & $\begin{array}{l}83 \cdot 8(862 / 1029) \\
87 \cdot 7(1965 / 1215) \\
89 \cdot 3(1042 / 1167)\end{array}$ & $\begin{array}{l}68 \cdot 6(706 / 1029) \\
75 \cdot 6(918 / 1215) \\
77 \cdot 8(908 / 1167)\end{array}$ & $\begin{array}{l}81 \cdot 7(841 / 1029) \\
83 \cdot 5(1015 / 1215) \\
84 \cdot 1(982 / 1167)\end{array}$ & $\begin{array}{l}62 \cdot 9(647 / 1029) \\
69 \cdot 4(843 / 1215) \\
71 \cdot 0(829 / 1167)\end{array}$ \\
\hline
\end{tabular}

$\star$ Data missing for 96 cases.

tData missing for 126 cases.

tData missing for 174 cases.

$\star \star$ Difference significant, $0.01<p<0.05 ; \star \star \star$ difference highly significant, $p<0.01$ 
Table 3 Independent odds ratio $(O R)(95 \%$ confidence interval (CI)) for each factor of completion of primary immunisation courses, estimated from logit model

\begin{tabular}{|c|c|c|c|c|}
\hline Factor & $\begin{array}{l}\text { DTPol } \\
(95 \% C I))\end{array}$ & $\begin{array}{l}\text { Pertussist (OR } \\
(95 \% \text { CI }))\end{array}$ & $\begin{array}{l}M M R \ddagger(O R \\
(95 \% C I))\end{array}$ & $\begin{array}{l}\text { All antigens } \delta(O R \\
(95 \% C I))\end{array}$ \\
\hline \multicolumn{5}{|l|}{ Sex } \\
\hline $\begin{array}{l}\text { Boys } \\
\text { Girls }\end{array}$ & $\begin{array}{l}1.0 \\
1.2(0.97 \text { to } 1.49)\end{array}$ & $\begin{array}{l}1.0 \\
1.2\end{array}$ & $\begin{array}{l}1.0 \\
0.99(0.82+01.19)\end{array}$ & 1.0 \\
\hline \multicolumn{5}{|l|}{ Family type } \\
\hline Two parents & $1 \cdot 0$ & 1.0 & $1 \cdot 0$ & $1 \cdot 0$ \\
\hline Lone parent & $0.55(0.44$ to 0.7$)$ & $0.58(0.48$ to 0.7$)$ & $0.55(0.44$ to 0.67$)$ & $0.59(0.50$ to 0.69$)$ \\
\hline \multicolumn{5}{|l|}{ Family position } \\
\hline First child & & $1 \cdot 0$ & $1 \cdot 0$ & $1 \cdot 0$ \\
\hline Second child & $0.49(0.37$ to 0.64$)$ & $0.48(0.39$ to 0.59$)$ & $0.59(0.46$ to 0.75$)$ & $0.56(0.46$ to 0.67$)$ \\
\hline Third child & $0.33(0.24$ to 0.46$)$ & $0.3(0.23$ to 0.38$)$ & $0.39(0.29$ to 0.51$)$ & $0.35(0.28$ to 0.49$)$ \\
\hline Fourth child and above & $0.24(0.17$ to 0.33$)$ & $0.23(0.17$ to 0.3$)$ & $0.28(0.21$ to 0.39$)$ & $0.27(0.21$ to 0.35$)$ \\
\hline \multicolumn{5}{|l|}{ Migration into Liverpool } \\
\hline Resident at birth & $1 \cdot 0$ & $1 \cdot 0$ & $1 \cdot 0$ & $1 \cdot 0$ \\
\hline Moved in since birth & $0.43(0.28$ to 0.66$)$ & $0.96(0.66$ to 1.4$)$ & $0.33(0.23$ to 0.48$)$ & $0.52(0.37$ to 0.73$)$ \\
\hline \multicolumn{5}{|l|}{ Deprivation } \\
\hline Per ODI unit & $0.96(0.92$ to 0.99$)$ & $0.95(0.92$ to 0.98$)$ & $0.99(0.96$ to 1.03$)$ & $0.96(0.94$ to 0.99$)$ \\
\hline
\end{tabular}

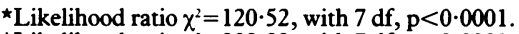

+ Likelihood ratio $\chi^{2}=202 \cdot 83$, with $7 \mathrm{df}, \mathrm{p}<0 \cdot 0001$.
†Likelihood ratio $\chi^{2}=125 \cdot 72$, with $7 \mathrm{df}, \mathrm{p}<0.0001$.

$\S$ Likelihood ratio $\chi^{2}=186 \cdot 12$, with $7 \mathrm{df}, \mathrm{p}<0 \cdot 0001$.

\section{INDEPENDENT EFFECT OF SOCIODEMOGRAPHIC VARIABLES}

Table 3 shows the independent effect (after allowing for the effect of the other variables) on course completion of each of the five variables. Pertussis was the only immunisation on which the child's sex had a significant independent effect, girls being more likely to complete the course than boys. In contrast, pertussis was the only antigen for which migration into Liverpool had no independent effect on course completion. Family position and family type independently affected completion of each individual antigen and the full set of antigens. The likelihood of completion decreased sharply with increasing number of older siblings and for children recorded as living with a lone parent. The deprivation index of the child's ward of residence had an independent effect on completion of the full set of antigens and on completion of DTPol and pertussis.

\section{IMPORTANCE OF CONSENT TO INVITATION}

Consent to invitation for immunisations is a key element of immunisation uptake. ${ }^{4}$ This point is emphasised by the very low number of children who subsequently completed courses when initial consent was not recorded (table 4). To assess the relative importance of recorded consent on course completion rates, we calculated antigen specific and composite completion rates among those children for whom consent was recorded (consent specific completion rates) (table 4).

Table 4 Consent specific completion rates

\begin{tabular}{|c|c|c|c|c|c|}
\hline \multirow[b]{2}{*}{ Antigen } & \multirow{2}{*}{$\begin{array}{l}\text { No }(\%) \text { consent } \\
\text { recorded } \\
(n=3585)\end{array}$} & \multicolumn{3}{|c|}{ Course completed } & \multirow{2}{*}{$\begin{array}{l}\text { Consent specific } \\
\text { completion rate } \\
(\mathrm{No}(\%))^{\star}\end{array}$} \\
\hline & & $\begin{array}{l}\text { Consent not } \\
\text { recorded }\end{array}$ & $\begin{array}{l}\text { Consent } \\
\text { recorded }\end{array}$ & Total & \\
\hline $\begin{array}{l}\text { Diphtheria } \\
\text { Tetanus } \\
\text { Polio } \\
\text { Pertussis } \\
\text { MMR } \\
\text { All antigens }\end{array}$ & $\begin{array}{l}3511(97 \cdot 9) \\
3514(98 \cdot 0) \\
3517(98 \cdot 1) \\
2976(83 \cdot 0) \\
3481(97 \cdot 1) \\
2941(82 \cdot 0)\end{array}$ & $\begin{array}{l}12 \\
12 \\
12 \\
29 \\
27 \\
42\end{array}$ & $\begin{array}{l}3118 \\
3122 \\
3117 \\
2635 \\
2960 \\
2397\end{array}$ & $\begin{array}{l}3130 \\
3134 \\
3129 \\
2664 \\
2987 \\
2439\end{array}$ & $\begin{array}{l}3118 / 3511(88 \cdot 8) \\
3122 / 3514(88 \cdot 8) \\
3117 / 3514(88 \cdot 7) \\
2635 / 2976(88 \cdot 5) \\
2960 / 3481(85 \cdot 0) \\
2397 / 2941(81 \cdot 5)\end{array}$ \\
\hline
\end{tabular}

^Excludes those for whom antigen specific consent was not recorded on the computer.
All the consent specific completion rates were lower than the national target of $90 \%$. The consent specific completion rate for the full set of antigens (83\%) was lower than for specific antigens. Consent specific completion of pertussis immunisation (89\%) equalled that of DTPol, whereas the consent specific completion rate for MMR was lower (85\%).

Table 5 shows consent specific completion rates for each antigen and for each of the five factors. Later family position, living with a lone parent, and migration into Liverpool were each associated with significantly lower consent specific completion rates for the full set of antigens and for individual antigens. This means that, among those who consented to be invited for immunisation, family position, family type, and migration had an effect on course completion over and above the effect of those factors on parental consent. The child's sex had no effect on course completion among children for whom consent was recorded. Local deprivation was associated only with completion of DTPol among those children for whom consent was given.

A comparison of tables 2 and 5 shows those instances in which significant differences in completion rates for the entire cohort of children were not mirrored in completion rates among children for whom consent was recorded. Thus although the child's sex and ward deprivation influenced cohort completion rates for pertussis, they did not influence completion of the vaccine among children for whom consent was given. In addition, although deprivation was associated with significantly lower cohort completion rates for the full set of antigens, this effect was not evident among those children whose parents gave consent to the full set of courses. This indicates the key part played by parental consent in immunisation uptake.

\section{Discussion}

The immunisation completion rates reported in this paper may be underestimates of the true situation. Despite there being a year between the youngest child's second birthday and the date of data extraction from the regional computer's 
Table 5 Sociodemographic factors and consent specific completion of primary immunisation courses

\begin{tabular}{|c|c|c|c|c|}
\hline \multirow[b]{2}{*}{ Factor } & \multicolumn{4}{|c|}{ Consent specific completion rate $(\%(N o))^{\star}$} \\
\hline & DTPol & Pertussis & $M M R$ & All antigens \\
\hline \multicolumn{5}{|l|}{ Sex } \\
\hline Girls & $89 \cdot 5(1501 / 1677)$ & $88.9(1291 / 1453)$ & $85 \cdot 5(1422 / 1663)$ & $82 \cdot 0(1175 / 1433)$ \\
\hline Boys & $87 \cdot 7(1608 / 1833)$ & $88 \cdot 2(1344 / 1523)$ & $84 \cdot 6(1538 / 1818)$ & $81 \cdot 0(1222 / 1508)$ \\
\hline Family position $\dagger$ & $\star \star \star$ & & & \\
\hline First child & $93 \cdot 8(1297 / 1382)$ & $93 \cdot 5(1162 / 1243)$ & $89 \cdot 6(1236 / 1379)$ & $86 \cdot 4(1065 / 1232)$ \\
\hline Second child & $88 \cdot 1(1012 / 1149)$ & $88.4(857 / 970)$ & $85 \cdot 5(964 / 1128)$ & $82 \cdot 3(786 / 995)$ \\
\hline Third child & $83 \cdot 6(463 / 554)$ & $82.9(355 / 428)$ & $79 \cdot 4(435 / 548)$ & $74.9(319 / 426)$ \\
\hline Fourth child and above & $80 \cdot 1(281 / 351)$ & $78 \cdot 7(210 / 267)$ & $75 \cdot 6(264 / 349)$ & $69 \cdot 3(185 / 267)$ \\
\hline Family typeł & $\star \star \star$ & $\star \star$ & $\star \star \star$ & $\star \star \star$ \\
\hline Lone parent & $86 \cdot 4(1078 / 1247)$ & $86 \cdot 9(888 / 1022)$ & $82 \cdot 1(1020 / 1242)$ & $79 \cdot 2(803 / 1014)$ \\
\hline Two parents & $90 \cdot 2(1944 / 2156)$ & $89 \cdot 8(1671 / 1860)$ & $87 \cdot 0(1854 / 2131)$ & $83 \cdot 4(1534 / 1840)$ \\
\hline Migration into Liverpool & 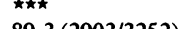 & & 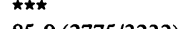 & \\
\hline Resident at birth & $89 \cdot 3(2903 / 3252)$ & $89 \cdot 2(2452 / 2749)$ & $85 \cdot 9(2775 / 3232)$ & $82 \cdot 6(2256 / 2732)$ \\
\hline $\begin{array}{l}\text { Moved in since birth } \\
\text { Deprivation } \$\end{array}$ & $\underset{\star \star}{79 \cdot 8}(206 / 258)$ & $80 \cdot 6(183 / 227)$ & $74 \cdot 3(185 / 249)$ & $67 \cdot 5(141 / 209)$ \\
\hline Most deprived & $86 \cdot 1(857 / 995)$ & $86 \cdot 8(699 / 805)$ & $84 \cdot 0(829 / 987)$ & $79.9(634 / 793)$ \\
\hline Deprived & $89.0(1063 / 1194)$ & $89.6(913 / 1019)$ & $85 \cdot 4(1006 / 1178)$ & $82.6(831 / 1006)$ \\
\hline Least deprived & $90 \cdot 3(1037 / 1148)$ & $88 \cdot 8(891 / 1003)$ & $85 \cdot 5(976 / 1142)$ & $81 \cdot 8(812 / 993)$ \\
\hline
\end{tabular}

*Number of children completing who were recorded on the computer as having consented. These figures therefore differ from the total number of children who completed the courses.

tData missing for 96 cases.

†Data missing for 96 cases.

†Data missing for 174 cases.

$\star \star$ Difference significant, $0.01<\mathrm{p}<0.05 ;{ }^{\star \star \star}$ difference highly significant, $\mathrm{p}<0.01$.

child health system, records of some antigens which had been given by the second birthday may not have been notified to the central information system. ${ }^{12}{ }^{13}$ Nevertheless, these are the data on which official returns to the Department of Health are made.

The low immunisation rate against pertussis and the significantly lower completion rates among boys and those children living in deprived areas of the city were direct reflections of the rate of consent to be invited for the immunisation. ${ }^{4}$ Clearly, national targets for pertussis immunisation will not be achieved in Liverpool until a greater proportion of parents give consent. Even among those children for whom consent was recorded, the $90 \%$ target was not reached. If children of parents who consent at the outset do not complete the course, efforts to increase consent among those sceptical of the value and importance of immunisations will not necessarily result in higher cohort completion rates. In contrast, differences in completion rates for DTPol and MMR for each sociodemographic factor were not directly attributable to differences in recorded consent.

There is conflicting evidence from other studies $^{13-16}$ as to whether children who move between health districts during the immunisation period are less likely to be fully immunised than those who stay within the health district of birth to be fully immunised. As discussed in our earlier paper, ${ }^{4}$ the significantly low completion rates identified in our study among children who moved into Liverpool may be partly 'fictional', 16 reflecting problems of information transfer between health districts. It is also possible, however, that those children who move into the district and whose immunisation records (including consent codes) are transferred, are less likely to be taken to clinics. This may reflect other practical priorities at the time of the move, lack of knowledge of primary care facilities, poor rapport with health professionals whom they have only recently met, or failure of computer generated reminders.

Family position and family type affected both recorded consent to, and subsequent course completion of, immunisations against all antigens. Lower completion rates after consent had been given among children with older siblings and in children living with a lone parent may reflect the practical difficulties encountered by parents (principally mothers) in attending clinics when the needs of several others must be included in their busy daily schedule. ${ }^{17}{ }^{18}$ The immediate costs in time and energy of clinic attendance may outweigh the perceived benefits, particularly if waiting times at clinics are unpredictable and long, and there are no play facilities for older children. ${ }^{19}$ Reliance on public transport may compound these problems. ${ }^{20}$ Lone parents are particularly likely to be living on low incomes and dependent on public transport. ${ }^{21}$ Even in car owning households, most women do not have use of the car during the day. ${ }^{20}$

Several papers have identified socioeconomic deprivation and lower social class as associated with significantly lower immunisation uptake rates. ${ }^{12}{ }^{1422-26}$ In this study, residence in a materially deprived ward was associated with lower completion rates of all antigens except MMR. These lower completion rates were largely a reflection of differences in recorded consent, however. ${ }^{4}$ This means that many parents living in materially deprived areas who give consent to immunisations are able to attend clinics, and further highlights the additional importance of household structure (as indicated by family size and type) in people's use of preventive health services.

Professionals need to be aware of particular parents' difficulties in attending immunisation clinics. Flexibility of service provision, in response to individual children's circumstances, is essential to achieve targets. Current trends towards practice based and locality purchasing of community child health services could improve access to immunisations by facilitating the more widespread and sensitive use of domiciliary services or opportunistic immunisation of infants when they are in contact with primary and community health care services. 
Finally, our study indicates that the composite - immunisation rate of children should be routinely calculated as an outcome measure for public health and health service management purposes, as concentration on individual antigens overestimates the immunisation status of our children.

Particular thanks to the Royal Liverpool Children's Hospital NHS Trust Research Review Group for financial support; to Mr Ron Morley, Mersey Regional Health Authority for support and advice in respect of the data; to Dr J L Hutton and Dr D Ashby for their in respect of the data; to Dr J L Hutton and Dr D Ashby for their
invaluable advice on statistical analysis; and to the City of Liverpool Planning Department for the ward ODI data.

1 Secretary of State for Health. The health of the nation. London: HMSO, 1991.

2 Department of Health. Vaccination and immunisation 1979 1989/90. Summary information from forms KC50, KC50A, 1989/90. Summary information from forms KC50, KCSOA, 1991 .

3 Liverpool Health Authority. Public health report 1990. Liverpool: Liverpool Health Authority, 1991.

4 Pearson M, Makowiecka K, Gregg J, Woollard J, Rogers M, West C. Primary immunisations in Liverpool. I: Who witholds consent? Arch Dis Child 1993; 69: 110-4

5 Department of Health. Immunisation against infectious disease. London: HMSO, 1992.

6 Health Departments of Great Britain. General practice in the National Health Service. The 1990 contract. London: Department of Health and Social Security, 1989.

7 Townsend $\mathrm{P}, \mathrm{Ph}$ illimore $\mathrm{P}$, Beattie A. Health and deprivation: inequality and the north. London: Croom Helm, 1988.

8 Dean AD, Dean JA, Burton JH, Dicker RC. Epi-Info, version 5: a word processing, database and statistics program for epidemiology on microcomputers. Atlanta: Centers for Disease Control, 1990.

9 Buchan I. Arcus Version 5.0. Users' booklet. Aughton: Medical Computing, 1989.

10 SAS Institute. SUGI supplemental library user's guide, version 5 edn. Cary, NC: SAS Institute, 1986: Ch 23.
11 Matthews DE, Farewell VT. Using and understanding medical statistics. Basle: Karger, 1985.

12 Mant D, Phillips A, Knightley M. Measles immunisation rates and the good practice allowance. $B M \mathcal{F} 1986 ; 293: 995-7$.

13 Jeffries S, McShane S, Overton J, Victor C, Beardow R. Low immunisation uptake rates in an inner-city health district: fact or fiction? F Public Health Med 1991; 13: 312-8.

14 Mant D, Phillips A, Knightley M. Measles immunisation rates and the good practice allowance. $B M \mathcal{F} 1986 ; 293$ : 995-7.

$15 \mathrm{Li} \mathrm{J}$, Taylor B. Comparison of immunisation rates in general i J, Taylor B. Comparison of immunisation rates in genera

practice and child health clinics. $B M \mathcal{A} 1991 ; 303$ : $1035-8$.
16 While A. Child health clinic attendance during the first two years of life. Public Health 1990; 104: 141-6.
yess

17 Coupland V. Gender, class and space as accessibility constraints from women with young children. Contemporary perspectives on health and health care. Occasional paper No 20. London: Department of Geography, Queen Mary College, 1982: 51-69.

18 Pearson M, Spencer S, McKenna M. Patterns of uptake and problems presented at well woman clinics in Liverpool. f Public Health Med 1991; 13: 42-57.

19 Pearson M, Dawson C, Moore H, Spencer S. Health on borrowed time? Prioritizing and meeting needs in lowborrowed time? Prioritizing and meeting needs in low1993; 1: 45-54.

20 Hamilton K, Jenkins L. Why women and travel? In: Grieco M, Pickup L, Whipp R, eds. Gender, transport and employment. Aldershot: Avebury Press, 1989: 115-26.

21 Popay J, Jones G. Patterns of health and illness amongst lone parents. Fournal of Social Policy 1990; 19: 499-534.

22 Peckham C, Bedford H, Senturia Y, Ades A. National immunisation study: factors influencing immunisation uptake in childhood. London: Action Research for the Crippled Child, 1989. (The Peckham report.)

23 New SJ, Senior ML. 'I don't believe in needles': qualitative aspects of a study into the uptake of infant immunisation in two English health authorities. Soc Sci Med 1991; 33: two En 509 -18.

24 Marsh GN, Canning DM. Deprivation and health in one general practice. $B M \mathcal{F}$ 1986; 292: 1173-6.

25 Jarman B, Bosanquet N, Rice P, Dollimore N, Leese B. Uptake of immunisation in district health authorities in England. $B M \mathcal{F}$ 1988; 296: 2775-8.

26 Gatrell A. Immunisation against whooping cough in Salford: a spatial analysis. Soc Sci Med 1986; 23: 1027-32. 